\title{
Association between transforming growth factor- $\beta 1$ expression and the clinical features of triple negative breast cancer
}

\author{
MING-JIAN DING ${ }^{1}, \mathrm{KE} \mathrm{SU}^{2}$, GUO-ZHONG CUI ${ }^{1}$, WEN-HUA YANG ${ }^{1}$, \\ LIANG CHEN $^{1}$, MENG YANG ${ }^{1}$, YAN-QING LIU ${ }^{1}$ and DIAN-LU DAI ${ }^{1}$ \\ ${ }^{1}$ Department of Oncology, Cangzhou Central Hospital, Cangzhou, Hebei 061000; ${ }^{2}$ Department of Nephrology, \\ Renmin Hospital of Wuhan University, Wuhan, Hubei 430071, P.R. China
}

Received February 3, 2015; Accepted March 1, 2016

DOI: $10.3892 / \mathrm{ol} .2016 .4497$

\begin{abstract}
The aim of the present study was to investigate the association between the expression levels of transforming growth factor- $\beta 1$ (TGF- $\beta 1$ ) and the clinical pathological characteristics and prognosis of triple negative breast cancer (TNBC) through study of TNBC patient tissue samples. The biological effects of TGF- $\beta 1$ on TNBC cells and the potential signal transduction pathway are additoinally investigated. Immunohistochemistry was utilized to investigate expression changes of the positive rate of TGF- $\beta 1$ in the TNBC, compared with the non-TNBC group, to explain the association between TGF- $\beta 1$ and clinical pathological characteristics and prognosis. MDA-MB-231 cells were treated with TGF- $\beta 1$ and subsequently the invasion and migration abilities, and the expression of proteins in certain signaling pathways were assessed before and after the treatment. Positive expression of TGF- $\beta 1$ was observed in $52.5 \%$ of TNBC tissue samples, which was higher than that observed in non-TNBC group (27.5\%). High levels of TGF- $\beta 1$ expression were not significantly associated age, menopausal status, family history of cancer or tumor size; however, tumor histological grade and axillary lymph node metastasis were significantly associated $(\mathrm{P}<0.05)$. In addition, when the TGF- $\beta 1$ expression levels are higher, the 5 -year disease-free survival rate is lower. TGF- $\beta 1$ expression promoted the invasion and migration of MDA-MB-231 cells, and the expression of Smad2 protein and P38 protein was increased, indicating that Smad2 protein and the P38 signaling pathway may serve an important role in TNBC.
\end{abstract}

Correspondence to: Mr. Dian-Lu Dai, Department of Oncology, Cangzhou Central Hospital, 16 Xinhua Road, Cangzhou, Hebei 061000, P.R. China

E-mail:dmj1984@126.com

Key words: TGF- $\beta$ 1, triple negative breast cancer, invasion, migration

\section{Introduction}

Transforming growth factor- $\beta 1$ (TGF- $\beta 1$ ) is a bioactive polypeptide cell factor. During tumor development, TGF- $\beta 1$ signaling imbalance or change may occur; as a result of a variety of cancer gene mutations, tumor cells secrete large amounts of active TGF- $\beta 1$, changing the micro-environment of tumor cells, and tumor invasion and metastasis is promoted. Triple negative breast cancer (TNBC), characterized by tumors that do not express estrogen receptor, progesterone receptor or human epidermal growth factor receptor 2 genes, represents a significant clinical challenge, as this type of cancer does not respond to endocrine therapy or other currently available targeted agents (1). The incidence of TNBC in terms of all breast cancer subtypes is $10-15 \%$ and the 10 -year survival is $74.8 \%(2,3)$. In general, survival rates tend to be lower with TNBC compared with other forms of breast cancer (4). TNBC is also more likely than other types of breast cancer to recur, particularly during the initial few years following treatment (1). Instead of hormone therapy, the treatment of TNBC often involves chemotherapy, radiation and surgery (2). The present study used immunohistochemistry to detect TGF- $\beta 1$ in TNBC specimens, and followed up the 5 year disease-free survival (DFS) rate, to elucidate the clinical features of TNBC with TGF- $\beta 1$ expression and its association with prognosis. In addition, MDA-MB-231 breast cancer cells were treated with $5 \mathrm{ng} / \mathrm{ml}$ TGF- $\beta 1$ and the invasion and migration ability were assessed as well as the protein expression levels of members of certain signal transduction pathways. The present study also aimed to provide a biological interpretation of the effects of high TGF- $\beta 1$ expression in TNBC cells using molecular biology teheniques.

\section{Materials and methods}

Patient selection, characteristics, treatment and follow up. A total of 80 patients were randomly selected from TNBC patients diagnosed at Cangzhou Central Hospital from June 2003 to June 2008. The patients were all female, 26-69 years old, the median age was 48.2 years, all patients were free from distant metastasis, and received parallel modified radical mastectomy for breast cancer with post-operative chemotherapy based on anthracycline and paclitaxel drug for 6-8 cycles. Those 
cases with $\geq 3$ axillary lymph node metastasis received local radiotherapy. Axillary lymph node metastasis was present in 49 cases, 6 cases presented with a family history of breast cancer. A total of 40 patients with non-TNBC were selected as a control group: All the patients in the control group had no evidence of distant metastasis, and received parallel operation resection, chemotherapy and radiotherapy for axillary lymph node metastasis, as above. The time of follow up was calculated from the time treatment was received to June 2013; the 5-year DFS rate for statistical analysis, which was assessed using a combination of telephone follow-up and out-patient review. The present study was approved by the Ethics Committee of Cangzhou Central Hospital (Cangzhou, China) and written informed consent was supplied by the participants.

Immunohistochemical experiments. Specimens were fixed with $10 \%$ formalin (Sigma-Aldrich, St. Louis, MO, USA) and prepared into $4-\mu \mathrm{m}$ thick sections, and were subjected to hemotoxylin and eosin staining and immunohistochemical staining. The sections were blocked using milk and incubated at room temperature for $2 \mathrm{~h}$, followed by incubation for $24 \mathrm{~h}$ at $4^{\circ} \mathrm{C}$ with rabbit polyclonal TGF- $\beta 1$ antibody (catalog no., BA0290; dilution, 1:2,000; Boster Biological Technology, Ltd., Wuhan, China). Samples were subsequently incubated with goat anti-rabbit biotinylated secondary immunoglobulin $\mathrm{G}$ antibody (dilution, 1:25; catalog no., BA1003; Boster Biological Technology, Ltd.) at room temperature for $1 \mathrm{~h}$. Negative controls were established following the same method but with the absence of primary antibodies. Immunohistochemistry used the Avidin-Biotin Complex (Boster Biological Technology, Ltd.) staining method to visualize the staining. TGF- $\beta 1$ expression predominantly appeared as diffuse or granular cytoplasmic staining. The sections were divided into groups based on the total proportion of positive cells: (-), No positive cells; $(+)$, positive cells in $<25 \%$; $(++), 25-75 \%$ positive cells; and $(+++),>75 \%$ positive cells. The pathological results were determines by two pathologists independently, where (-) and (+) groups were defined as the low expression group, and (++) and $(+++)$ groups were defined as the high expression group.

Cells derived and cultured. MDA-MB-231 cells were purchased from Boster Biological Technology, Ltd., seeded at a density of $1 \times 10^{6}$ and cultured with L-15 culture medium (Gibco; Thermo Fisher Scientific, Inc., Waltham, MA, USA) at $37^{\circ} \mathrm{C}$ with $5 \% \mathrm{CO}_{2}$.

Cell invasion and migration assays. MDA-MB-231 cells $\left(1 \times 10^{6}\right)$ were treated with $5 \mathrm{ng} / \mathrm{ml}$ TGF- $\beta 1$ or L- 15 alone as a control. A BD Matrigel ${ }^{\mathrm{TM}}$ Basement Membrane Matrix (BD Biosciences, San Jose, CA, USA) was used to detect changes in invasive ability, according to the manufacturer's protocol. The relative number of invasive cells was used to indicate the cell invasion ability, the experiment was repeated three times, and the mean is presented. Migration was assessed using a Transwell chamber assay according to the previously described protocol (5), similar to the invasion experiment.

Western blot analysis of signaling pathway protein expression. MDA-MB-231 cells were treated with $5 \mathrm{ng} / \mathrm{ml}$ TGF- $\beta 1$ and total protein was extracted with cell lysis buffer (Thermo
Fisher Scientific, Inc.), $25 \mu \mathrm{g}$ protein was separated by $10 \%$ sodium dodecyl sulfate polyacrylamide gel electrophoresis, the proteins were transferred to film. The polyvinylidene difluoride membrane was blocked by non-fat milk at $37^{\circ} \mathrm{C}$ for $24 \mathrm{~h}$, and then incubated overnight at $4^{\circ} \mathrm{C}$ with the following antibodies: Rabbit polyclonal anti-Smad2 (dilution, 1:1,000; catalog no., ab192175; Abcam, Cambridge, UK), rabbit polyclonal anti-p38 (dilution, 1:1,000; catalog no., ab38238; Abcam), rabbit polyclonal anti p-Smad2 (dilution, 1:800; catalog no., 3101; Cell Signaling Technology, Inc., Danvers, MA, USA) and rabbit monoclonal anti p-p38 (dilution, 1:800; catalog no., 9215; Cell Signaling Technology, Inc.). The membrane was then incubated with horseradish peroxidase-conjugated goat anti-mouse polyclonal secondary antibody (dilution, 1:5,000; catalog no., ab6789; Abcam) or horseradish peroxidase-conjugated goat anti-rabbit polyclonal secondary antibody (dilution, 1:5,000; catalog no., ab6721; Abcam) at room temperature for $2 \mathrm{~h}$. The protein bands were visualized using DAB reagent (BD Biosciences), and images were captured using a Vilber-Fusion chemiluminescence system (Molecular Imaging Vilber Fusion X7; Vilber Lourmat Deutschland, Eberhardzell, Germany) and analyzed using Image J software version 1.48 (imagej. nih.gov/ij/index.html). The optical density ratio comparing the expression of each target protein prior to and following TGF- $\beta 1$ treatment was recorded, and $\beta$-actin was used as a control. The experiment was repeated 3 times.

Statistical analysis. Data was analyzed using single factor analysis of variance using multiple indexes between the two indexes or an unpaired students $t$ test. $\mathrm{P}<0.05$ was considered to indicate a statistically significant difference. Kaplan-Meier curves were generated and used to perform survival analysis. Data analysis was performed using SPSS software, version 19.0 (IBM SPSS, Inc., Chicago, IL, USA).

\section{Results}

The expression levels of TGF- $\beta 1$ in the TNBC tissues. A total of 42 TNBC cases expressed TGF- $\beta 1$ at a high level (52.5\%), while the TGF- $\beta 1$ expression rate in non-TNBC patients was $27.5 \%$ ( $\mathrm{t}=6.759 \mathrm{P}<0.005)$ (Fig. 1).

Association between TGF- $\beta 1$ expression and clinical features of TNBC patients. No significant associations were observed between high TGF- $\beta 1$ expression levels and age, menopausal status, tumor, family history or tumor size. However, high TGF- $\beta 1$ expression levels were associated with tumor histological grade $(\mathrm{P}<0.0001)$ and axillary lymph nodes $(\mathrm{P}=0.001)$ metastasis (Table I).

$D F S$. The 5 year DFS rate was assessed by the Kaplan-Meier method. The 5-year DFS was significantly higher in the TGF- $\beta 1$ low expression group compared to the high expression group (Fig. 2).

Effect of TGF- $\beta 1$ treatment on MDA-MB-231 invasion ability and migration. MDA-MB-231 cells were treated with $5 \mathrm{ng} / \mathrm{ml}$ TGF- $\beta 1$ compared with the control group. The number of cells invading through the membrane was increased following TGF- $\beta 1$ treatment $(227.22 \pm 26.1$ versus $168.11 \pm 22.53$ cells; 
Table I. Expression of TGF- $\beta 1$ in triple negative breast cancer.

\begin{tabular}{|c|c|c|c|c|}
\hline Clinical features & $\begin{array}{c}\text { TGF- } \beta 1 \\
\text { (high expression) }\end{array}$ & $\begin{array}{c}\text { TGF- } \beta 1 \\
\text { (low expression) }\end{array}$ & $\chi^{2}$ & P-value \\
\hline Age, years & & & 0.001 & 1.000 \\
\hline$>50$ & 20 & 18 & & \\
\hline$<50$ & 22 & 20 & & \\
\hline Menopausal & & & 3.193 & 0.111 \\
\hline Non menopausal & 20 & 25 & & \\
\hline Post-menopausal & 22 & 13 & & \\
\hline Family history & & & 0.956 & 0.416 \\
\hline Yes & 2 & 4 & & \\
\hline No & 40 & 34 & & \\
\hline Tumor size, $\mathrm{cm}$ & & & 0.856 & 0.437 \\
\hline$<2$ & 14 & 9 & & \\
\hline $2-5$ & 20 & 21 & & \\
\hline$>5$ & 8 & 8 & & \\
\hline Lymph node & & & 11.178 & 0.001 \\
\hline Positive & 33 & 16 & & \\
\hline Negative & 9 & 22 & & \\
\hline Histological grading & & & 39.679 & $<0.0001$ \\
\hline I-II & 8 & 34 & & \\
\hline III & 34 & 4 & & \\
\hline
\end{tabular}

TGF- $\beta 1$, transforming growth factor- $\beta 1$.
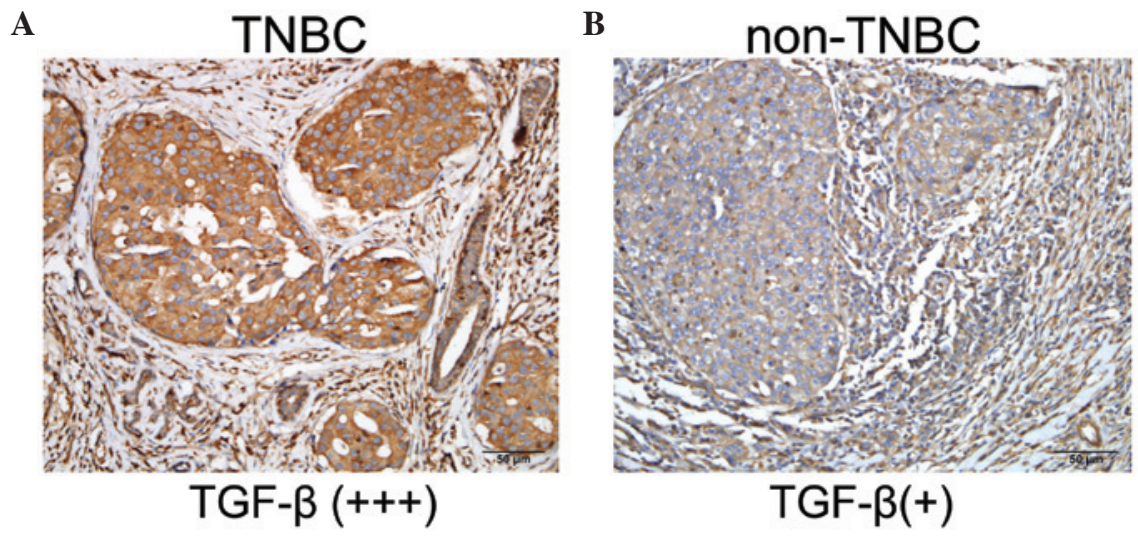

Figure 1. Expression of TGF- $\beta 1$ in breast cancer tissues: positive expression of TGF- $\beta 1$ in TNBC tissues is higher than in the non-TNBC group (A) high expression of TGF- $\beta 1$ in tissues of breast cancer (B) low expression of TGF- $\beta 1$ in tissues of breast cancer. TGF- $\beta 1$, transforming growth factor- $\beta 1$; TNBC, triple negative breast cancer.

$\mathrm{P}<0.05)$ and migration was also significantly increased $(217.22 \pm 17.23$ versus $157.78 \pm 17.23 ; \mathrm{P}<0.05)$ (Table II).

Changes in expression of signalling proteins in MDA-MB-231 following TGF- $\beta 1$ treatment. The protein expression levels of Smad2, phosphorylated Smad2, P38 protein and phosphorylated P38 were significantly increased in the MDA-MB-231 cells treated with TGF- $\beta 1$ compared with the control group $(\mathrm{P}<0.05)$. These results suggest that the cell biology effect of TGF- $\beta 1$ on TNBC involves the Smad 2 and P38 signal transduction pathways (Fig. 3).

\section{Discussion}

TGF- $\beta 1$ demonstrates a dual role in the malignant tumor development process $(6,7)$. During the early stages of carcinogenesis, TGF- $\beta 1$ exhibits a predominantly inhibitory effect on growth, and serves as a tumor suppressor. However, with the development of malignancy, TGF- $\beta 1$ promotes tumor cell invasion and metastasis $(8,9)$. Previous studies have demonstrated that high expression levels of TGF- $\beta 1$ have a close association with gastric cancer (10), lung cancer (11), colon cancer $(10,12)$ and other malignant tumors. However, 
Table II. Effect of TGF- $\beta 1$ on the invasion and migration of MDA-MB-231 cells.

\begin{tabular}{lcccr}
\hline & Treatment group $^{\mathrm{a}}$ & Control group $^{\mathrm{a}}$ & T-value & P-value \\
\hline Invasion assay & $227.22 \pm 26.18$ & $168.11 \pm 22.53$ & 5.136 & $<0.05$ \\
Migration assay & $217.22 \pm 17.23$ & $157.78 \pm 17.23$ & 8.336 & $<0.05$ \\
\hline
\end{tabular}

${ }^{a}$ Number of cells passing through Transwell membrane. TGF- $\beta 1$, transforming growth factor- $\beta 1$.

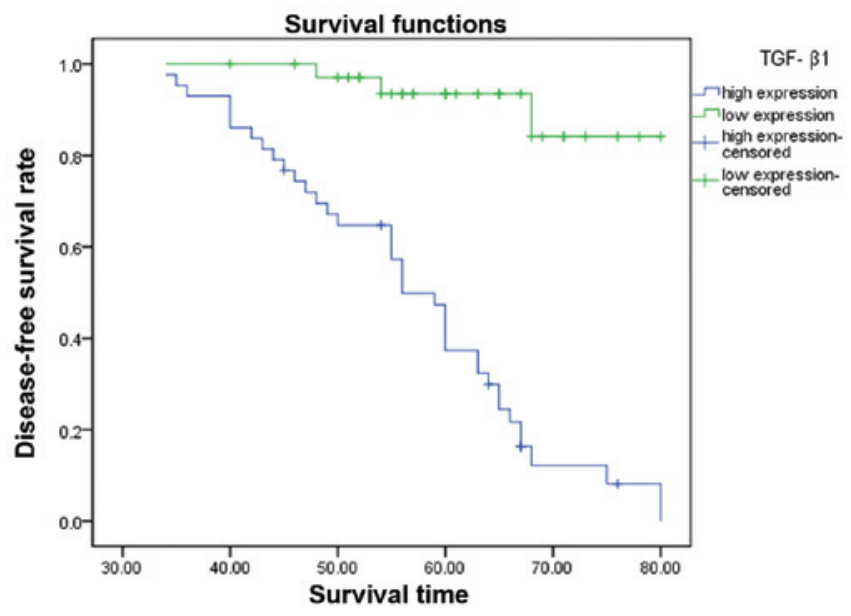

Figure 2. The difference between TGF- $\beta 1$ high expression group and low expression group on 5-year DFS. The low expression of TGF- $\beta 1$ group had a longer DFS compared to those with high expression levels. TGF- $\beta 1$, transforming growth factor- $\beta 1$; DFS, disease-free survival.

the association between TGF- $\beta 1$ expression and TNBC has not been established.

TNBC typically has an early age of onset and the risk of recurrence is high (1). TNBC tumor cells do not express the estrogen and progesterone receptor or Her-2 gene; as such, there is no clinically specific endocrine therapy or targeted drug therapy available for TNBC (2). In the present study, the expression of TGF- $\beta 1$ was significantly higher in TNBC tissues compared to that of non-TNBC tissues. I $n$ vitro, Transwell invasion and migration assays demonstrated that migration and invasion were increased in the TNBC cell line MDA-MB-231 cells when the cells were treated with $5 \mathrm{ng} / \mathrm{ml}$ TGF- $\beta 1$ compared with the control group. Therefore, high expression levels of TGF- $\beta 1$, may serve an important role in promoting TNBC development; it may also contribute to the high malignancy and high rate of metastasis and recurrence of TNBC.

Bao et al (13) demonstrated that increased TGF- $\beta 1$ expression level in breast cancer, were associated with increased axillary lymph node metastasis, and the average survival time was reduced. Similarly, in the present study, 80 samples from TNBC patients were analyzed and it was demonstrated that high expression levels of TGF- $\beta 1$ were associated with worse histological grade and increased axillary lymph node metastasis. A study by Lang et al (14) also confirmed this point. In the present study, survival curves were produced using the Kaplan-Meier method and demonstrated that the 5-year DFS rate was significantly lower in patients with high TGF- $\beta 1$ expression levels compared to patients with low expression
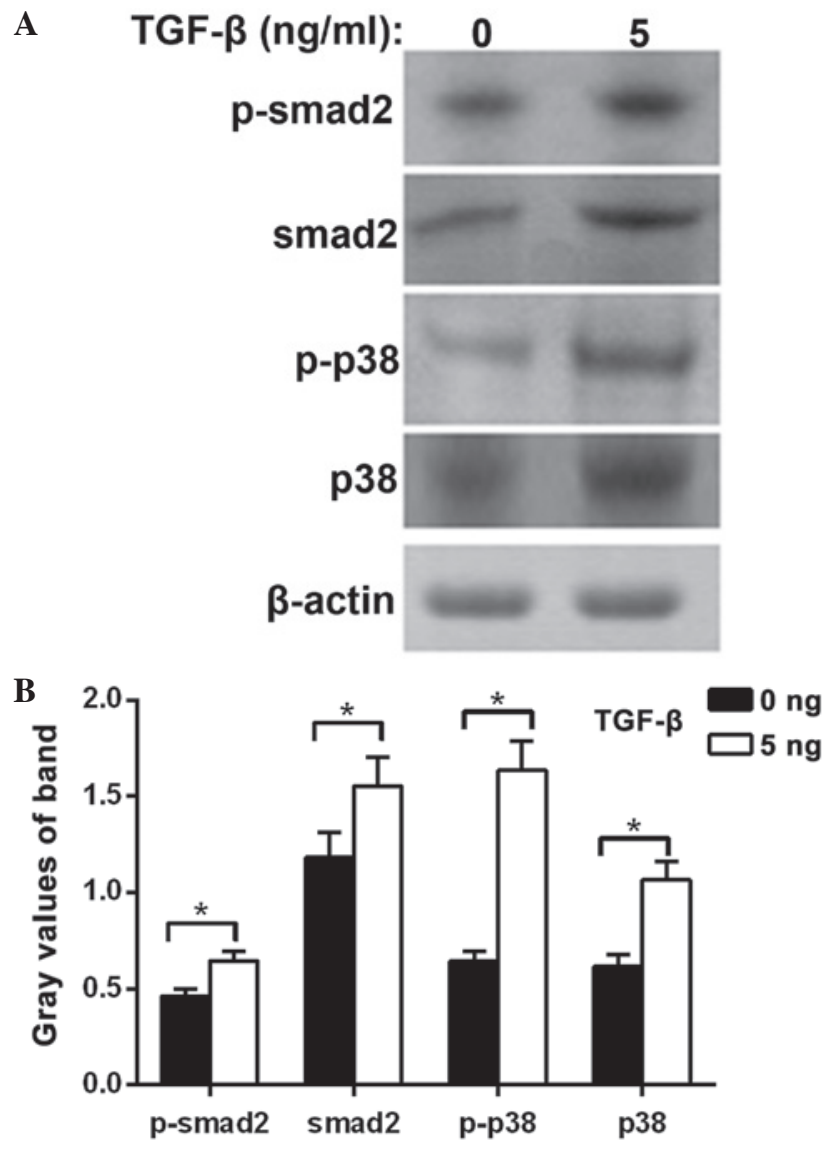

Figure 3. Influence of TGF- $\beta 1$ on TNBC cell signal transduction pathways. (A) MDA-MB-231 cells were treated with $5 \mathrm{ng} / \mathrm{ml}$ TGF- $\beta 1$ and then analyzed by western blot analysis. Smad2 protein and phosphorylation of Smad2 protein, $\mathrm{P} 38$ protein and phosphorylation of $\mathrm{P} 38$ protein band were increased in cells treated with TGF- $\beta 1$. (B) Densitometric analysis of the western blot. Experiments were performed in triplicate $(" \mathrm{P}<0.05)$. TGF- $\beta 1$, transforming growth factor- $\beta 1$; TNBC, triple negative breast cancer.

levels, suggesting that the TGF- $\beta 1$ expression content of TNBC tissue may be a potential prognostic biomarker. Although the evidence in the present study and other previous studies indicates that the content and expression levels of TGF- $\beta 1$ in TNBC tissues may be involved in the occurrence and development of TNBC, the mechanism by which TGF- $\beta 1$ expression is upregulated in tumor invasion and metastasis remains unclear.

It is generally considered that TGF- $\beta 1$ expression in normal cells depends on the Smad-TGF- $\beta 1$ signaling pathway and the independent Smad independent pathways in equilibrium; both can regulate TGF- $\beta 1$ expression mutually, and in tumor cells this balance is disrupted $(15,16)$. Xue et al (17) confirmed that the TGF- $\beta 1$-mediated Smad signaling pathway is involved in tumor recurrence and metastasis. Lang et al (14) demonstrated 
that TGF- $\beta 1$ participates in the recurrence and metastasis of breast cancer via urokinase type plasminogen activator (uPA) and plasminogen activator inhibitor (PAI-1) activation. The P38 protein is an important member of the mitogen activated protein kinase (MAPK) protein family, it is a member of the Smad-independent signaling pathway that activates TGF- $\beta 1$ (18); uPA and PAI-1 P38 protein is involved in the recurrence and metastasis of breast cancer (19). Following treatment of MDA-MB-231 cells with TGF- $\beta 1$, the protein expression levels of P38 and Smad2 were increased as well as their corresponding phosphorylated proteins, suggesting that the P38 pathway and Smad2 pathway may serve important roles in the effects of TGF- $\beta 1$ on promoting cell invasion and migration. The effects of TGF- $\beta 1$ on promoting aggressive behavior in TNBC cells may involve the interaction of multiple genes and numerous pathways, and therefore the role of TGF- $\beta 1$ signaling requires further study.

\section{Acknowledgements}

The authors thank Miss Ke SU, Mr Guo-zhong Cui, Mr Meng Yang, Miss Yanqing Liu, Mr Dianlu Dai for advice and discussion; Mr Wen-hua Yang, Mr Liang Chen for critical reading of the manuscript; and Mr Meng Yang, Miss Yanqing Liu for excellent technical assistance.

\section{References}

1. Kumar P and Aggarwal R: An overview of triple-negative breast cancer. Arch Gynecol Obstet 293: 247-269, 2016.

2. Cleator S, Heller W and Coombes RC: Triple-negative breast cancer: Therapeutic options. Lancet Oncol 8: 235-244, 2007.

3. Bao P, Peng P, Gu K, Wu C, Huang Z, Gong Y, Zhang M and Zheng Y: Long-term survival analysis of different breast cancer molecular subtypes: Shanghai Breast Cancer Survival Study. Zhonghua Wai Ke Za Zhi 53: 928-934, 2015 (In Chinese).

4. Lund MJ, Trivers KF, Porter PL, Coates RJ, Leyland-Jones B, Brawley OW, Flagg EW, O'Reagan RM, Gabram SG and Eley JW: Race and triple negative threats to breast cancer survival: A population-based study in Atlanta, GA. Breast Cancer Res Treat 113: 357-370, 2009.
5. Marshall J: Transwell(®) invasion assays. Methods Mol Biol 769: 97-110, 2011.

6. Bierie B and Moses HL: Transforming growth factor beta (TGF-beta) and inflammation in cancer. Cytokine Growth Factor Rev 21: 49-59, 2010.

7. Padua D and Massagué J: Roles of TGF-beta in metastasis. Cell Res 19: 89-102, 2009.

8. Bierie B and Moses HL: Gain or loss of TGFbeta signaling in mammary carcinoma cells can promote metastasis. Cell Cycle 8: 3319-3327, 2009.

9. Nagaraj NS and Datta PK: Targeting the transforming growth factor-beta signaling pathway in human cancer. Expert Opin Investig Drugs 19: 77-91, 2010.

10. Coban S, Yüksel O, Koçkar MC, Köklü S, Basar O, Tutkak H and Ormeci $\mathrm{N}$ : The significance of serum transforming growth factor beta 1 in detecting of gastric and colon cancers. Hepatogastroenterology 54: 1472-1476, 2007.

11. Minamiya Y, Miura M, Hinai Y, Saito H, Ito M, Ono T, Toda H, Motoyama $\mathrm{S}$ and Ogawa J: Transforming growth factor- $\beta 1$ $29 \mathrm{~T}>\mathrm{C}$ genetic polymorphism is associated with lymph node metastasis in patients with adenocarcinoma of the lung. Tumour Biol 31: 437-441, 2010.

12. Bellam N and Pasche B: Tgf-beta signaling alterations and colon cancer. Cancer Treat Res 155: 85-103, 2010.

13. Bao J, Wu ZS, Qi Y, Wu Q and Yang F: Expression of TGF-betal and the mechanism of invasiveness and metastasis induced by TGF-beta1 breast cancer. Zhonghua Zhong Liu Za Zhi 31: 679-682, 2009 (In Chinese).

14. Lang DS, Marwitz S, Heilenkötter U, Schumm W, Behrens O, Simon R, Reck M, Vollmer E and Goldmann T: Transforming growth factor-beta signaling leads to uPA/PAI-1 activation and metastasis: A study on human breast cancer tissues. Pathol Oncol Res 20: 727-732, 2014

15. Kajdaniuk D, Marek B, Borgiel-Marek H and Kos-Kudła B: Transforming growth factor- $\beta 1$ (TGF $\beta 1$ ) in physiology and pathology. Endokrynol Pol 64: 384-396, 2013.

16. Heldin CH, Landström M and Moustakas A: Mechanism of TGF-beta signaling to growth arrest, apoptosis and epithelialmesenchymal transition. Curr Opin Cell Biol 21: 166-176, 2009.

17. Xue J,Lin X, Chiu WT, Chen YH, Yu G, Liu M,Feng XH, Sawaya R, Medema RH, Hung MC and Huang S: Sustained activation of SMAD3/SMAD4 by FOXM1 promotes TGF- $\beta$-dependent cancer metastasis. J Clin Invest 124: 564-579, 2014.

18. Taylor MA, Parvani JG and Schiemann WP: The pathophysiology of epithelial-mesenchymal transition induced by transforming growth factor-beta in normal and malignant mammary epithelial cells. J Mammary Gland Biol Neoplasia 15: 169-190, 2010.

19. Shin BA, Yoo HG, Kim HS, Kim MH, Hwang YS, Chay KO, Lee KY, Ahn BW and Jung YD: P38 MAPK pathway is involved in the urokinase plasminogen activator expression in human gastric SNU-638 cells. Oncol Rep 10: 1467-1471, 2003. 